\title{
2011 CSHP National Awards Program Winners Programme national des prix 2011 de la SCPH : lauréats et lauréates
}

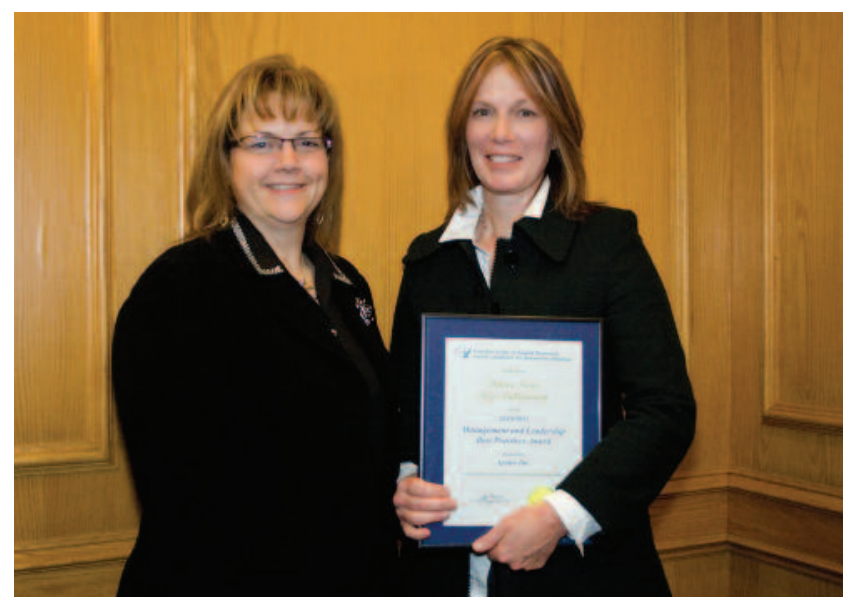

Management and Leadership Best Practices Award

Apotex Inc

Danica Irwin (right; recipient) with Julie Berdusco (left), Apotex Inc (coauthor not present: Régis Vaillancourt)

Development of a Pediatric Emergency Department Outreach Website to

Promote Standardized Pediatric Medication Prescribing across a Local Health Integration Network

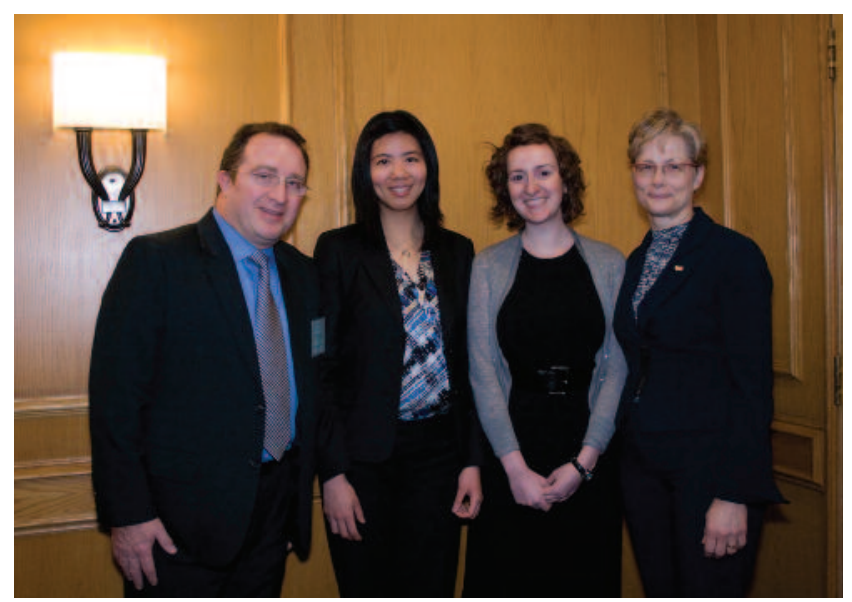

\section{Patient Care Enhancement Award}

AstraZeneca Canada Inc

Jennifer Chen (middle left), Sara Rosaline Lavoratore (middle right), and L Lee Dupuis (right) with George DeAngelis (left), Director, Pricing and Contracting Department, AstraZeneca Canada Inc (coauthor not present: Sabrina Boodhan)

A Reliable Method of Obtaining Blood Samples from Implantable Central Venous Catheters for Determination of Plasma Gentamicin Concentrations

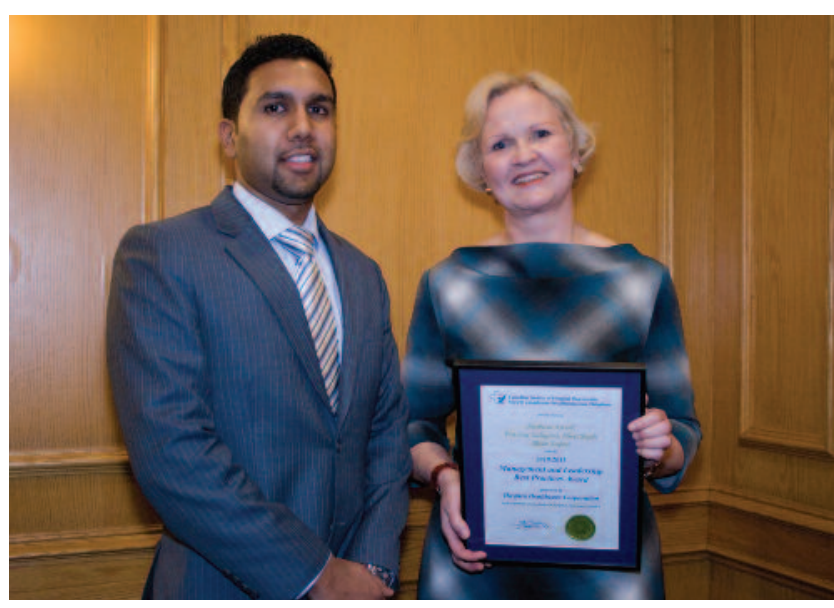

Management and Leadership Best Practices Award Hospira Healthcare Corporation

Barbara Sproll (right; recipient) with Rommel Gajadhar (left), Area Manager, Specialty Pharmaceuticals, Hospira Healthcare Corporation (coauthors not present: Cenzina Caligiuri, Sheri Dyck, and Blair Seifert) Development and Implementation of a Regional Program for the Safe Handling of Hazardous Drugs by Hospital Pharmacies

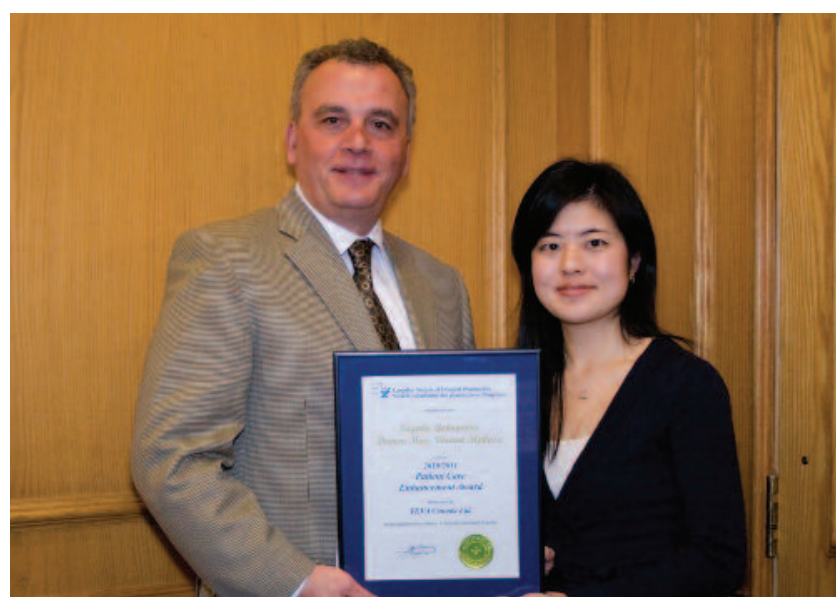

Patient Care Enhancement Award

TEVA Canada Ltd

Sayako Yokoyama (right; recipient) with Jim Lazenka (left), Hospital Account Specialist, TEVA Canada Ltd (coauthors not present: Damen Man and Vincent $H$ Mabasa)

An Analysis of QTc Prolonging Medication Orders Belonging to Intensive and Cardiac Care Unit Patients with Pre-existing QTc Prolongation (QTIPPP Study) 


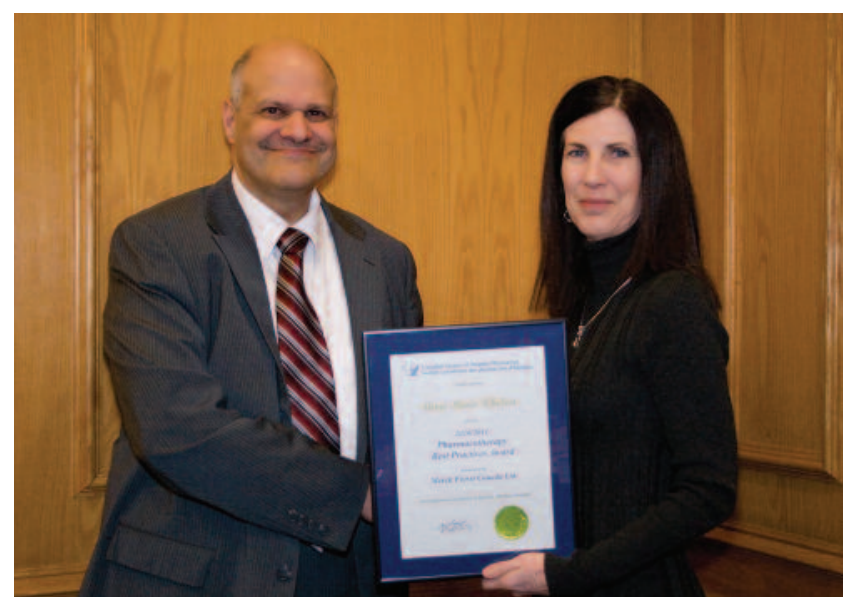

Pharmacotherapy Best Practices Award

Merck Frosst Canada Ltd

Anne Marie Whelan (right; recipient) with Jimmy Ghadiali (left), Senior Product Manager, Anesthesia and Institution Strategy,

Merck Frosst Canada Ltd

Development and Evaluation of an Instrument for the Critical Appraisal of Randomized Controlled Trials of Natural Products

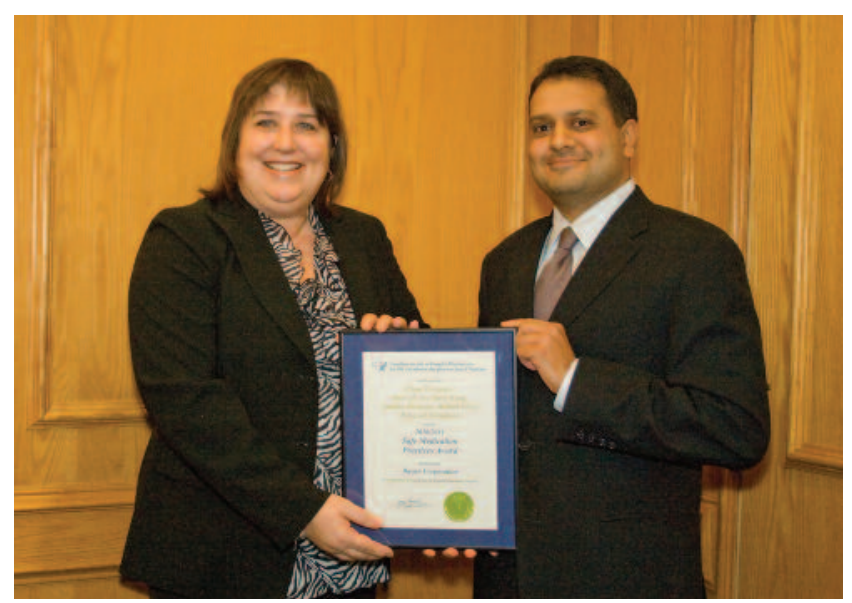

Safe Medication Practices Award

Baxter Corporation

Olavo Fernandes (right; recipient) with Dominique Gagnon (left),

Business Unit Manager, Baxter Corporation (coauthors not present Anna W Lee, Gary Wong, Jennifer Harrison, Michael Wong, and Margaret Colquhoun)

What Is the Impact of a Centralized Provincial Drug Profile Viewer on the Quality and Efficiency of Patient Admission Medication Reconciliation? A Randomized Controlled Trial

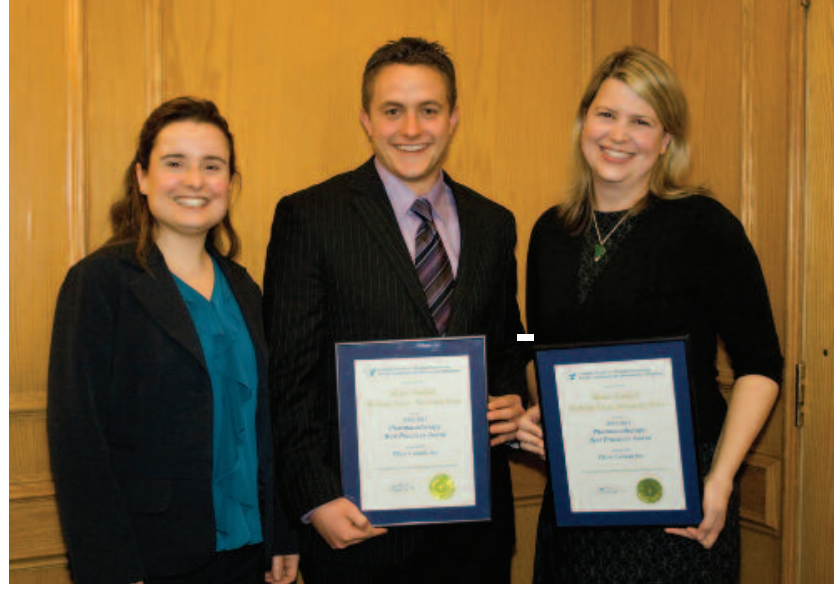

Pharmacotherapy Best Practices Award Pfizer Canada Inc

Shane Pawluk (centre) and Roxane Carr (right) (recipients) with Geneviève Pelletier (left), National Manager, Pharmacy Relations, Pfizer Canada Inc (coauthor not present: Roberta Esau)

Single versus Double Gram Negative Coverage Empiric Antibiotic Therapy of Febrile Neutropenia in Pediatric Patients

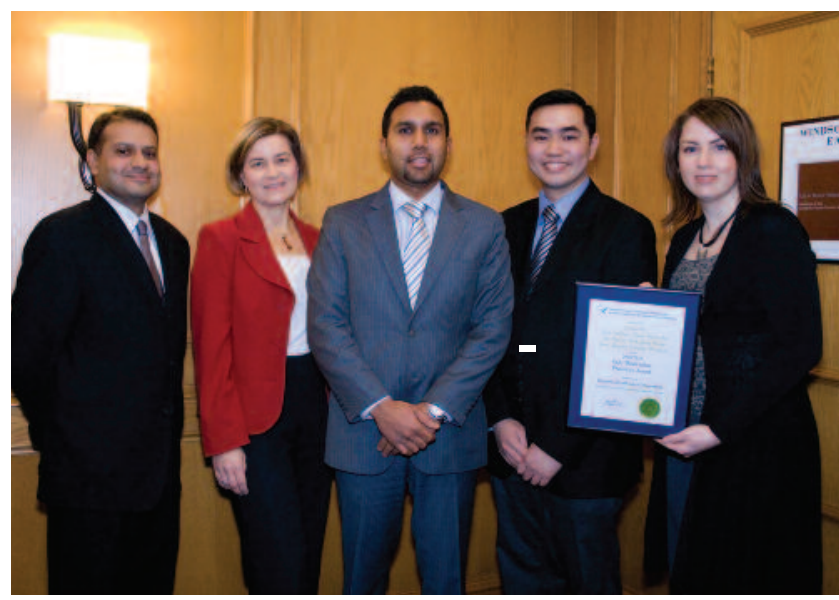

Safe Medication Practices Award

Hospira Healthcare Corporation

Olavo Fernandes (left), Jana Bajcar (middle left), Justin Lee (middle right), and Kori Leblanc (right) (recipients) with Rommel Gajadhar (centre), Area Manager, Specialty Pharmaceuticals, Hospira Healthcare Corporation (coauthors not present: Jin-Hyeun Huh, Gary Wong, and Jennifer Harrison)

Medication Reconciliation during Internal Hospital Transfer and Impact of Computerized Prescriber Order Entry 


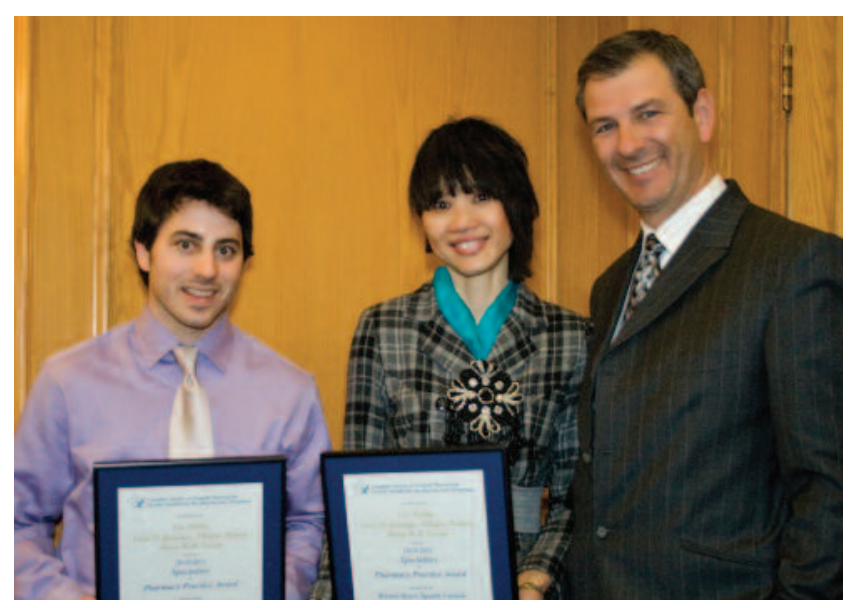

Specialties in Pharmacy Practice Award

Bristol-Myers Squibb Canada

Eric Poulin (left) and Mary H H Ensom (centre) (recipients) with Donald Allard (right), Director of Government Relations and Public Affairs, Bristol-Myers Squibb Canada (coauthors not present:

Erica D Greanya and Nilufar Partovi)

Development and Validation of Limited Sampling Strategies for Tacrolimus and Mycophenolate in Steroid-Free Renal Transplant Regimens

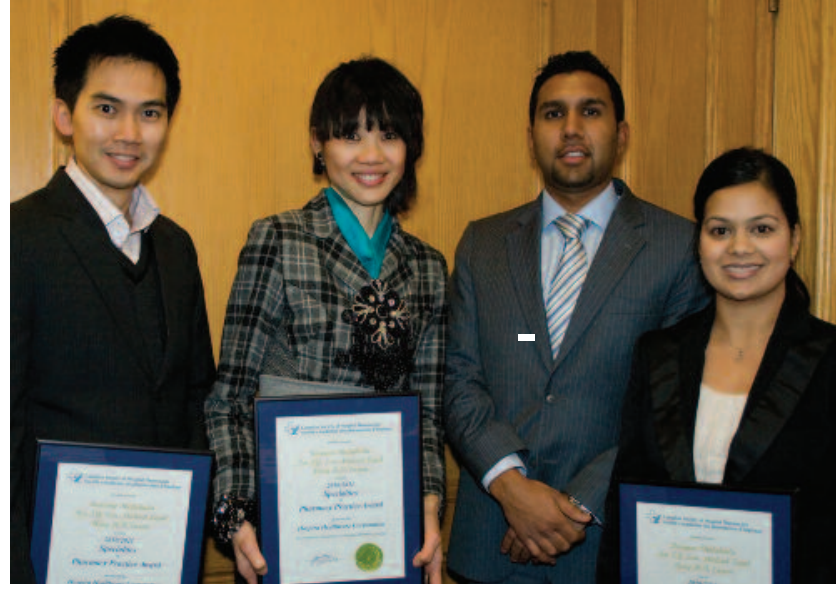

Specialties in Pharmacy Practice Award

Hospira Healthcare Corporation

Tim T Y Lau (left), Mary H H Ensom (middle left), and Rosanne

Thalakada (right) (recipients) with Rommel Gajadhar (middle right), Area Manager, Specialty Pharmaceuticals, Hospira Healthcare

Corporation (coauthor not present: Michael Legal)

Development of a Novel Vancomycin Dosing Nomogram for Achieving High-Target Pre-Dose Levels at Two Major Canadian Teaching Hospitals

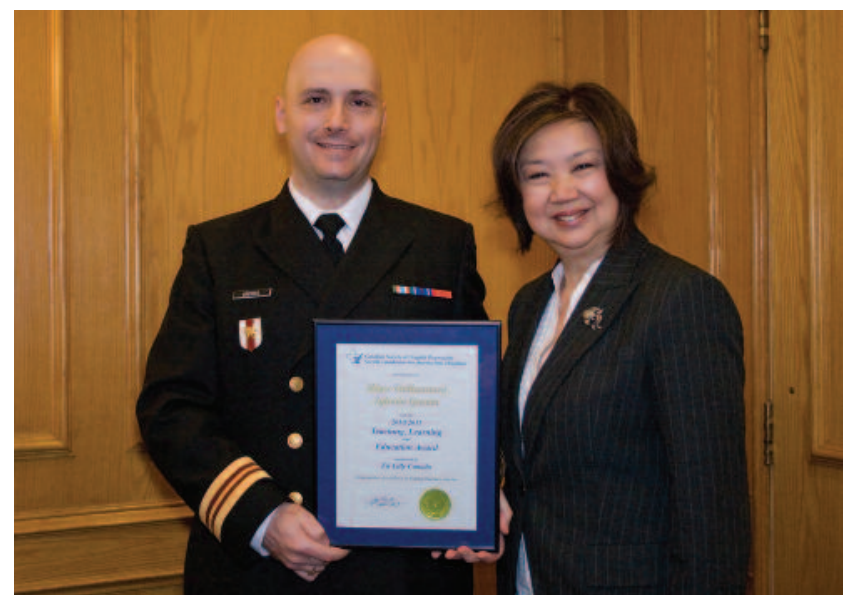

Teaching, Learning, and Education Award

Eli Lilly Canada

Sylvain Grenier (left; recipient) with Linda Chow (right), Manager, Strategic Partnership Group-West, Eli Lilly Canada (coauthor not present: Régis Vaillancourt)

International Pictogram Project for the Labelling of Medication 